\title{
Deformation Resistance of Palatal Plate Connectors in Removable Partial Dentures
}

\section{OANA CELLA ANDREI ${ }^{1}$, IOANA TARLUNGEANU ${ }^{1}$, LIVIA ALICE TANASESCU ${ }^{1}$, ADRIANA BISOC ${ }^{1}$, MIHAI BURLIBASA ${ }^{2}$, CATALINA FARCASIU ${ }^{3}$, MAGDALENA NATALIA DINA ${ }^{2}$, ADINA MAGDALENA BUNGET ${ }^{4}$, RUXANDRA MARGARIT 5}

${ }^{1}$ Carol Davila University of Medicine and Pharmacy, Faculty of Dentistry, Department of Removable Prosthodontics, 37 Dionisie Lupu Str., 020021, Bucharest, Romania

${ }^{2}$ Carol Davila University of Medicine and Pharmacy, Faculty of Midwifery and Nursing, Department of Dental Techniques, 37 Dionisie Lupu Str., 020021, Bucharest, Romania

${ }^{3}$ Carol Davila University of Medicine and Pharmacy, Faculty of Dentistry, Department of Pedodontics, 37 Dionisie Lupu Str., 020021, Bucharest, Romania

${ }^{4}$ University of Medicine and Pharmacy, Faculty of Dentistry, Department of Prevention of Oro-Dental Diseases, 2 Petru Rares Str., 200349, Craiova, Romania

${ }^{5}$ Carol Davila University of Medicine and Pharmacy, Faculty of Dentistry, Department of Restorative Odontotherapy,

37 Dionisie Lupu Str., 020021, Bucharest, Romania

\begin{abstract}
The aim of our study was to evaluate the deformation resistance of two palatal plate type connectors of removable partial dentures and to make a comparison between the reduced palatal plates and the large ones, in terms of bending resistance during function. We tested 10 maxillary class I Kennedy removable partial dentures made for real clinical cases and duplicated their connectors, 5 of each type. A Universal Loading Machine was used to apply a bilateral progressive force to the PM2-M1 area until the samples bended, recording the force value at which the first change occurred. The results were analyzed using the ANOVA method. For the reduced palatal plate group, the minimum bending force value was $1584 \mathrm{~N}$, the maximum bending force value being $2920 \mathrm{~N}$. For the large palatal plate group, the minimum bending force value was $3150 \mathrm{~N}$, the maximum value being $3380 \mathrm{~N}$. Statistical analysis of data using the ANOVA method shows that the results are statistically relevant, with a $p$ value of $0,001031(p<0,05)$. The results showed that decreasing the width of the palatal plate can have a significant effect on the deformation resistance of the major connector and can affect its rigidity; in clinical practice, these results can help dentists to use alternative appropriate design methods of increasing the rigidity of reduced palatal plates, in order to protect both the remaining structures and the acrylic components of the dentures during the years of its functioning.
\end{abstract}

Keywords: palatal plate, removable partial denture, deformation resistance

\section{Introduction}

Palatal plate type connectors of removable partial dentures (RPD) cover half or more of the palate contributing to the wide distribution of stresses coming from the acrylic parts of the removable partial dentures (in our cases, artificial acrylic teeth and saddles). Their role is to connect metallic and acrylic parts in order to ensure support, retention and stabilization of the denture; therefore, one of their most important features is rigidity during the entire period of the denture's function. The design of the cast palatal plates must be rigorously made by the dentist in order to distribute stresses adequately and to protect the remaining teeth, the residual bone and the acrylic parts from the potentially harmful lever and torque effect of the denture. Therefore, rigidity is very important in order to maintain the periodontal support, the residual ridge and the overlying tissues for as many years as possible [1]. Nevertheless, their thickness negatively influences patient's comfort, so the rigidity must be obtained as much as possible by augmenting the width of the strap, positioned between the vibrating line and rugae, in clinical cases where torus is absent. In order to remain rigid during the entire functioning period of the denture, the width of the palatal plate is classically considered to have to be designed 
proportionally to the length of the acrylic saddle and edentulous space. Still, in practice, most of the maxillary plate type major connectors are made with a reduced width, avoiding the extensive palatal coverage, and as thin as possible (for comfort). The aim of this study is to evaluate the deformation resistance of the palatal plate type major connectors in maxillary class I Kennedy removable partial dentures, comparing the reduced plate with the large one, and to analyze the differences in bending resistance between the different widths of the palatal strap, in order to help dentists to choose the best way to design these connectors.

Choosing a palatal plate type maxillary major connector in class I Kennedy edentulous cases must be made keeping in mind the need to maximize the palatal support and to obtain rigidity [2]. The form and dimensions of the palatal plates are also depending on the specific anatomical situation of each patient, which is influencing rigidity; finite element analysis studies were made that demonstrated that for wide and shallow palate it is necessary to design a reinforced palatal strap [3]. The reduced palatal plate (strap) is the most used major connector by the dentists, being positioned on the central area of the palate; it is preferred by the patients because it is narrow, does not interfere with phonetics and has a minimal gingival coverage. Relief is required if a bony midline exists. In order to be used in class I Kennedy RPDs, it should be designed very bulky in order to resist deformation and that would severely interfere with the patient's comfort. A study made by Pienkos et al. that tried to determine the minimum major connector dimensions that would provide adequate functional strength concluded that it is safe to reduce the dimensions of some other major connectors under normal loads, but not of the palatal strap; still, even for the other types of connectors, the study revealed that the denture risks deformations when dropped from a height [4].

A study on 15 patients made by Arigbede et al. showed that the palatal plate was the last in patient's preferences, after the most preferred metal bar connector and the much less preferred acrylic resin plate [5]; the conclusion is that palatal coverage is not usually agreed by the patients and can be a reason why, in practice, the reduced palatal plate is more frequently used than the large one.

The second connector we tested is the large palatal plate. Comfort of the patient is positively affected by the fact that it can be designed very thin; the negative aspect is the excessive palatal coverage that some patients may not agree with. In some clinical cases, because it is extending in the three planes of the vault (the horizontal part, the lateral slopes and the anterior slope of the palate), this type of major connector has a great resistance to deformation. Studies showed that the most rigid maxillary major connector is the anteroposterior palatal bar, used in class III and IV Kennedy RPDs, and being placed on different vertical and horizontal planes [6,7]; the full palatal plate and the palatal strap that can be used in class I and II Kennedy RPDs follow. The dimension of a large palatal plate is very close to that of the full palatal plate, which is offering maximum tissue support and therefore it is the connector of choice in long distal extension cases, with few remaining natural teeth, long acrylic saddles and the majority of dental units restored by acrylic artificial teeth.

\section{Materials and methods}

The study was carried out on a number of 10 upper class I Kennedy removable partial dentures, with saddles and artificial teeth made of thermoplastic PMMA, made for 10 real clinical cases, all having palatal plate type major connectors that were duplicated for the experiment. All connectors were made of the same Co-Cr alloy. To ensure similarity to oral conditions, we simulated mucosal resilience with a putty condensation silicone that exhibits elasticity after setting. Samples were subjected to a bilateral progressive force applied to the PM2-M1 area. The flexural load was applied until the samples bended, recording the force value at which the first change occurred. A Universal Loading Machine (Lloyd Instruments) was used, with a maximum force of $5 \mathrm{kN}$ and a crosshead speed of $1.0 \mathrm{~mm} / \mathrm{min}$ (Figure 1). NEXYGEN Data Analysis Software was used to record the results. A representative bended specimen is shown in Figure 2. The graphics show the dependency between load and extension for each sample, recording the force value at which the deformation occurred. The results were statistically analyzed using the ANOVA method. Statistical analysis of data using the 
ANOVA method uses the $p$ value to evaluate the relevance of the results; in our experiment this value is under 0.05 , which means it is statistically relevant in regards to the differences between deformation resistance among the two types of major connectors.

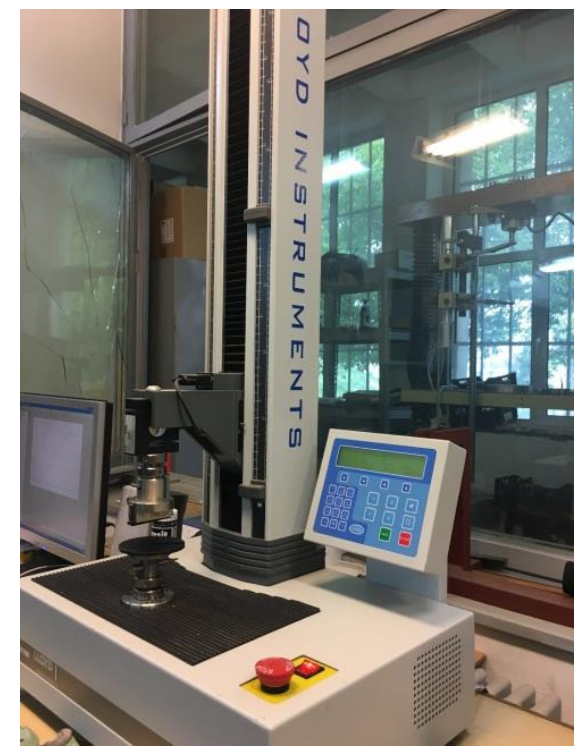

Figure 1. The universal Loading Machine (Lloyd Instruments)

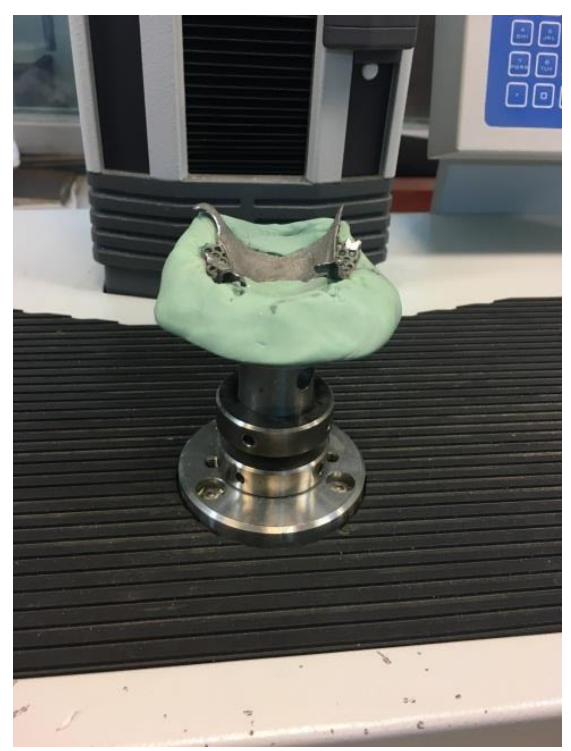

Figure 2. Bended specimen from the large palatal plate group

Table 1. Bending force values for the reduced palatal plate type major connectors

\begin{tabular}{|c|c|c|c|c|}
\hline 1 & 2 & 3 & 4 & 5 \\
\hline $1584 \mathrm{~N}$ & $1635 \mathrm{~N}$ & $1684 \mathrm{~N}$ & $2120 \mathrm{~N}$ & $2920 \mathrm{~N}$ \\
\hline
\end{tabular}

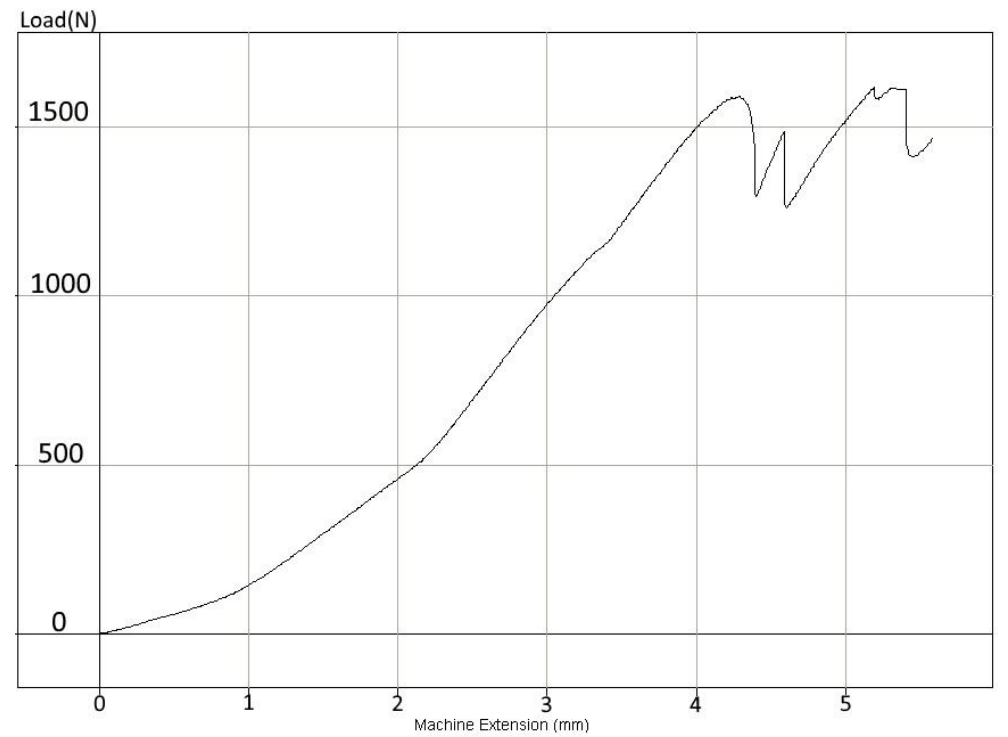

Figure 3. The minimum deformation force value for the reduced palatal plate group

\section{Results and discussions}

For the reduced palatal plate group, the minimum bending force value was $1584 \mathrm{~N}$, the maximum bending force value being $2920 \mathrm{~N}$, with an average of $1988.6 \mathrm{~N}$ plus/minus $562.64 \mathrm{~N}$ (the standard deviation). Bending force values for the reduced palatal plate group is shown in Table 1. The graph with the minimum bending force values is shown in figure 3 and the maximum in Figure 4. 


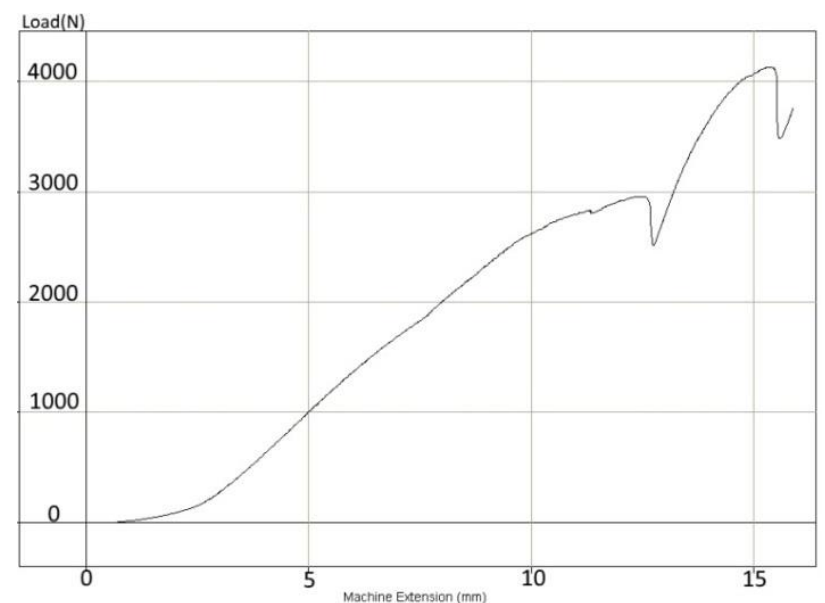

Figure 4. The maximum deformation force value for the reduced palatal plate group

Table 2. Bending force values for the large palatal plate type major connectors

\begin{tabular}{|c|c|c|c|c|}
\hline 1 & 2 & 3 & 4 & 5 \\
\hline $3150 \mathrm{~N}$ & $3208 \mathrm{~N}$ & $3264 \mathrm{~N}$ & $3340 \mathrm{~N}$ & $3380 \mathrm{~N}$ \\
\hline
\end{tabular}

For the large palatal plate group, the minimum bending force value was $3150 \mathrm{~N}$, the maximum value being $3380 \mathrm{~N}$, with an average of $3268.4 \mathrm{~N}$ plus/minus $93.89 \mathrm{~N}$ (the standard deviation). Bending force values for the large palatal plate group are shown in Table 2. The graph with the minimum bending force value is shown in figure 5 and the maximum in Figure 6.

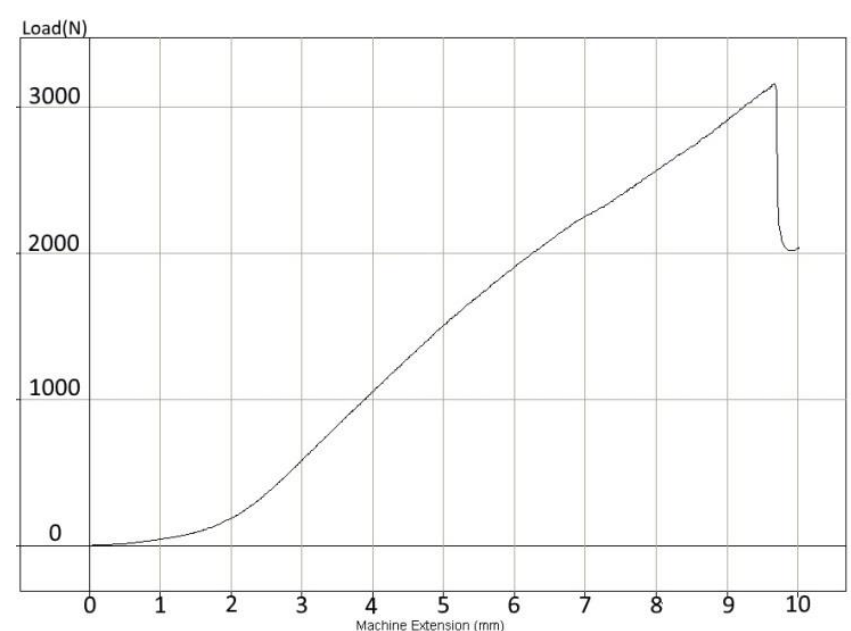

Figure 5. The minimum deformation force value for the large palatal plate group

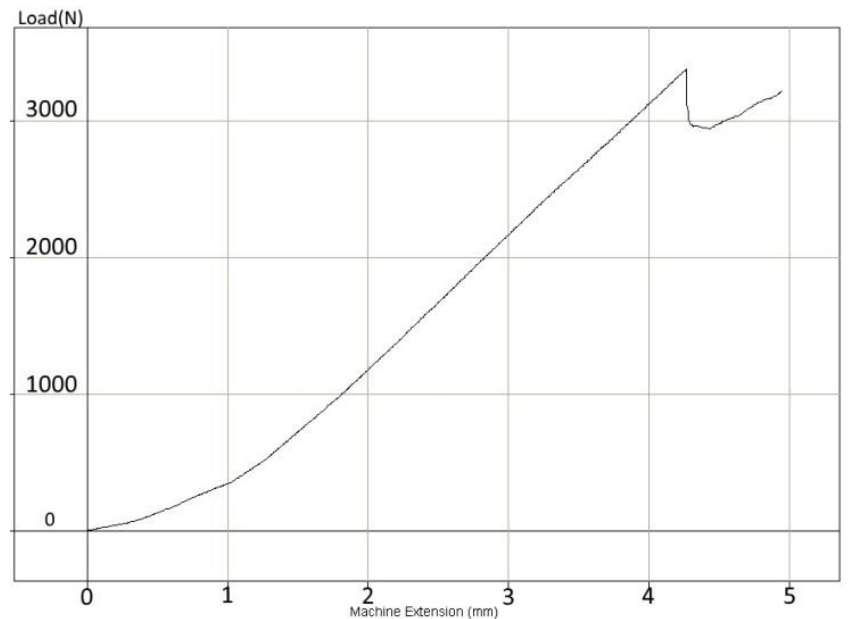

Figure 6. The maximum deformation force value for the large palatal plate group

The comparison between the deformation resistances of the two types of palatal plates is shown in Table 3. The difference between the mean value of deformation resistance of the reduced palatal plate and the large palatal plate groups is significant. Statistical analysis of data using the ANOVA method shows that the results are statistically relevant, with a $p$ value of $0,001031(p<0,05)$ (Table 4), in regards to the differences between deformation resistance among the two types of major connectors. The connectors from the reduced palatal plate group proved to be significantly more susceptible to bending, while those pertaining to the large palatal plate group were more resistant to deformation. 
Table 3. Comparison between the deformation resistances of the two types of major connectors

\begin{tabular}{|c|c|c|}
\hline & Reduced palatal plate & Large palatal plate \\
\hline standard deviation & 562.6471363 & 93.8978168 \\
\hline mean & 1988.6 & 3268.4 \\
\hline median & 1684 & 3264 \\
\hline
\end{tabular}

Table 4. The ANOVA method and $p$ value

\begin{tabular}{|c|c|c|c|c|c|c|}
\hline \multicolumn{5}{|l|}{$\begin{array}{l}\text { Anova: Single Factor } \\
\text { SUMMARY }\end{array}$} & & \\
\hline Groups & Count & Sum & Average & Variance & & \\
\hline Column 1 & 5 & 9943 & 1988.6 & 316571.8 & & \\
\hline Column 2 & 5 & 16342 & 3268.4 & 8816.8 & & \\
\hline \multicolumn{7}{|l|}{ ANOVA } \\
\hline Source of Variation & SS & $d f$ & $M S$ & $F$ & $P$-value & $F$ crit \\
\hline Between Groups & 4094720.1 & 1 & 4094720 & 25.16818 & 0.001031 & 5.317655 \\
\hline Within Groups & 1301554.4 & 8 & 162694.3 & & & \\
\hline Total & 5396274.5 & 9 & & & & \\
\hline
\end{tabular}

In a finite element analysis study, Todorovic et al. demonstrated that occlusal forces are transmitted from the acrylic parts through the major connector mostly to the abutment teeth [8], which underlines the importance of the major connector's rigidity in protecting the remaining structures; these findings confirmed previous results obtained by Kaires AK [9]. Eto et al. studied deflections in thirteen major maxillary RPD-s connectors using finite element analysis and found that rigid connectors are the most effective in transmitting applied simulated occlusal forces to the contralateral side of the framework [10]. Other authors that performed rigidity tests on mandibular and maxillary major connectors found that the most rigid maxillary major connector was the anterior-posterior palatal bar and the most flexible was the U-shaped palatal bar [11]. Ozkan and Aydin investigated the deformation of four maxillary Kennedy class I major connectors, analyzed comparatively by two methods, and found that the palatal strap and the palatal plate presented microscopic cracks located at the depth of the palate [12]. Previous studies tested some types of mandibular and maxillary major connectors, investigating their stiffness in compression and torsion tests and finding that maxillary major connectors were more rigid in compression compared to the mandibular ones, while in torsion the highest rigidity was found in maxillary palatal plate with large width and in mandibular double bar [13].

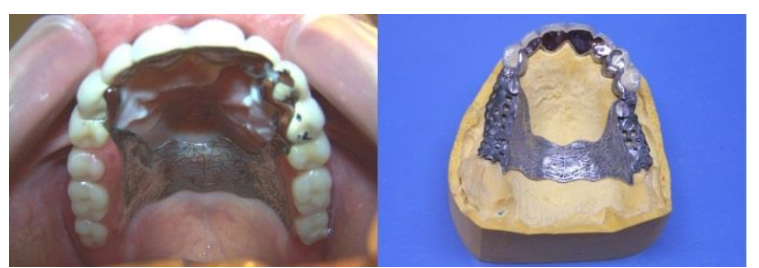

Figure 7. Reduced palatal plate for a removable partial maxillary denture -the clinical case and the duplicated connector 

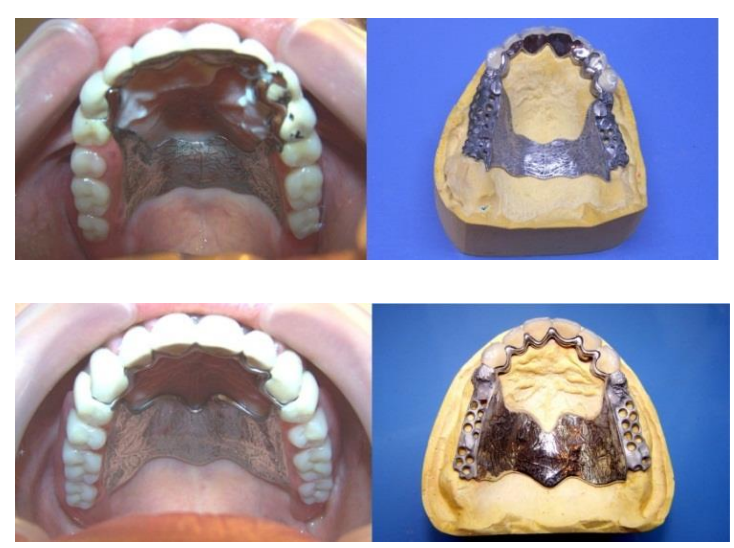

Figure 7. Reduced palatal plate for a removable partial maxillary denture -the clinical case and the duplicated connector

Figure 8. Large palatal plate for a removable partial maxillary denture- the clinical case and the duplicated connector

A palatal plate type major connector's rigidity depends on the casting alloy, on the anatomy of the palatal bone and on the design. Despite the increasing use of titanium in dentistry, most major connectors are still made from Co-Cr alloys, which proved to be the most effective in ensuring rigidity at the same dimensions. In a study made by Aridome et al., the authors compared the bending properties of major connectors made from strengthened $\mathrm{Ti}-6 \mathrm{Al}-7 \mathrm{Nb}$ alloy, which has a poor rigidity, with those made from $\mathrm{Co}-\mathrm{Cr}$ alloy, in an attempt to improve them using different methods of design and to make them available as an option for clinical application [14]. The modified design included making the connector wider, thicker, thick in the middle and thick in the anterior and posterior borders. Other authors used a Universal testing machine to compare Co-Cr upper major connectors widely used in clinical situations with Titanium (CP-Ti) ones, finding that using titanium for major connectors is risky from the casting point of view and also that an equivalent rigidity cannot be obtained without seriously altering the design [15]. For the Co-Cr alloy, only the central area of the plate can be thicker for an increased rigidity, without notably affecting the comfort; some authors concluded that the effect of thickness is more significant than the width and also that the casting technique is influencing the rigidity of the connectors [16].

The anatomy of the palatal vault greatly influences the major connector's design, making it difficult for the dentists to correctly choose its dimensions [17]. In a study made by Hallikerimath et al. measuring sixty stone casts of partially edentulous maxillary arches, the five resulted threedimensional finite element models were given different framework designs for the same Co-Cr alloy's properties. The analysis evaluated deflection in single palatal strap major connectors depending on the different shapes of the palatal vault. Still, the results were mixed, some of them suggesting increasing the width of the strap and reinforcing it, while others suggested decreasing the width [18], proving that making the correct design of the major connector for each clinical case is a difficult task for the dentists [19]. A clinical study made by Bosinceanu et al. revealed that partial removable dentures made of nylon superpolyamide are a viable option versus the ones using $\mathrm{Co}-\mathrm{Cr}$ alloy connectors [20].

\section{Conclusions}

Within the limits of our study, we can conclude that decreasing the width of the palatal plate has a significant effect on the deformation resistance of the major connector and can affect its rigidity; in clinical practice, these results can help dentists to use other design methods of increasing the rigidity of reduced palatal plates, such as making thicker the central area of the plate or the anterior and posterior borders.

\section{References}

1. CARR, A.B., BROWN, D.T., McCracken's removable partial prosthodontics. 12th ed., Elsevier Mosby, St. Louis, 2010, chapter 5:29-55.

2. LA VERE, A.M., KROL, A.J., Selection of a major connector for the extension-base removable partial denture. J Prosthet Dent. 2005; 94:207-8. 
3. TAKANASHI, T., SHIMAMURA, I., SAKURAI, K., Influence of width and depth of palatal vault on rigidity of palatal strap: A finite element study. J Prosthodont Res. 2009 Apr;53(2):95-100.

4. PIENKOS, T.E., MORRIS, W.J., GRONET, P.M., CAMERON, S..M, LOONEY, S.W., The strength of multiple major connector designs under simulated functional loading. J Prosthet Dent 2007 May;97(5):299-304.

5. ARIGBEDE, A.O., DOSUMU, O.O., ESAN, T.A., AKEREDOLU, P.A., Acceptability of maxillary major connectors in removable partial dentures. Afr Health Sci. 2006 Jun;6(2):113-117.

6. BEN-UR, Z., MIJIRITSKY, E., GORFIL, C., BROSH, T., Stiffness of different designs and crosssections of maxillary and mandibular major connectors of removable partial dentures. J Prosthet Dent 1999 May;81(5):526-32.

7. BHOJARAJU, N., SRILAKSHMI, J., VISHWANATH, G., Study of deflections in maxillary major connectors: a finite element analysis. J Indian Prosthodont Soc 2014 Jan-Mar;14(1):50-60.

8.TODOROVIC, A., RADOVIC, K., GRBOVIC, A., RUDOLF, R., MAKSIMOVIC, I., STAMENKOVIC, D., Stress analysis of a unilateral complex partial denture using the finite-element method, Mater. Tehnol. 2010;44(1):41-47.

9. KAIRES, A.K., Effect of partial denture design on bilateral force distribution. J Prosthet Dent 1956;7:197-205.

10. ETO, M., WAKABAYASHI, N., OHYAMA, T., Finite element analysis of deflections in major connectors for maxillary RPDs. Int J Prosthod. 2002; Sep-Oct;15(5):433-8.

11. BEN-UR, Z., MATALON, S., AVIV, I., CARDASH, H.S., Rigidity of major connectors when subjecting to bending and torsion forces. J Prosthet Dent. 1989 Nov;62(5):557-62.

12. ÖZKAN, P., AYDIN, A.K., Comparison of Deformation by Stereophotogrammetry of Various Kinds of Major Connectors in Maxillary Kennedy Class I Removable Partial Dentures. Int J Prosthod. 2001 Jan-Feb;14(1):71-6.

13. ANDREI, O.C., MUSTEATA, M.A., MIHAESCU, C.S., MIU, M.C., Evaluarea rigiditatii prin teste de compresiune si torsiune a unor tipuri de conectori principali maxilari si mandibulari. Rev Rom St. 2012; 3:181-189.

14. ARIDOME, K., YAMAZAKI, M., BABA, K., OHYAMA, T., Bending properties of strengthened Ti-6Al-7Nb alloy major connectors compared to Co-Cr alloy major connectors. J Prosthet Dent. 2005 Mar;93(3):267-73.

15. LEE, Y.J., VANG, M.S., YANG, H.S., PARK, S.W., PARK, H.O., LIM, H.P., Comparison of rigidity and castability in different designs of maxillary major titanium framework. $\mathrm{J}$ Korean Acad Prosthodont. 2007Aug;45(4):431-443.

16. HATIM, N.A., AL-ALI, A.A., Strength, hardness, corrosion evaluation and computer-aided designing of cobalt-chromium molybdenum maxillary major connectors. J Coll Dentistry 2005;17(1):24-9.

17. GAD, M.M., Removable partial denture designing: variations of hard and soft tissue anatomy and maxillary major connector selection. Int J Dentistry Oral Sci. 2017;4(4):457-63.

18. HALLIKERIMATH, R.B., MALLIKARJUN, H.D., PATIL, V., KUMAR, V.S., Evaluation of deflection in single palatal strap major connector as influenced by different shapes of palatal vault: A three-dimensional finite element study. J Int Oral Heath 2015;7(10):53-57.

19. POLYCHRONAKIS, N., SOTIRIOU, M., ZISSIS, A., A survey of removable partial denture casts and major connector designs found in commercial laboratory, Athens, Greece. J Prosthodont 2013 Apr;22(3):245-9.

20.BOSINCEANU, D.G., SANDU, I.G., BACIU, E.R., BOSINCEANU, D.N., SURLARI, Z., MARTU, I., BALCOS, C., BOLAT, M., Flexible acrylate dentures versus Chromium Cobalt removable partial dentures - a viable therapeutical solution. Mater. Plast., 56(1), 2019, 120-123.

$\overline{\text { Manuscript received: 8.12.2019 }}$ 